\title{
Hydrogels Improve Plant Growth in Mars Analog Conditions
}

\section{Frédéric Peyrusson *}

Pharmacologie Cellulaire et Moléculaire, Louvain Drug Research Institute, Université catholique de Louvain, Brussels, Belgium

OPEN ACCESS

Edited by:

Lucie Poulet,

NASA Postdoctoral Program,

United States

Reviewed by:

Josep M. Trigo-Rodríguez,

Consejo Superior de Investigaciones

Cientificas (CSIC), Spain

Roberta Paradiso,

University of Naples Federico II, Italy

Wieger Wamelink,

Wageningen University and Research,

Netherlands

*Correspondence:

Frédéric Peyrusson

frederic.peyrusson@uclouvain.be

Specialty section:

This article was submitted to

Astrobiology,

a section of the journal

Frontiers in Astronomy and Space

Sciences

Received: 22 June 2021

Accepted: 28 October 2021

Published: 18 November 2021

Citation:

Peyrusson F (2021) Hydrogels Improve

Plant Growth in Mars

Analog Conditions.

Front. Astron. Space Sci. 8:729278.

doi: 10.3389/fspas.2021.729278
Sustainable human settlement on Mars will require in situ resource utilization (ISRU), the collection and utilization of Mars-based resources, including notably water and a substrate for food production. Plants will be fundamental components of future human missions to Mars, and the question of whether Mars soils can support plant growth is still open. Moreover, plant cultivation may suffer from the lack of in situ liquid water, which might constitute one of the biggest challenges for ISRU-based food production on Mars. Enhancing the crop yield with less water input and improving water utilization by plants are thus chief concern for sustainable ISRU food production. Hydrogels are polymers able to absorb large quantity of water and to increase soil water retention, plant establishment and growth. This work reports on the short-term assessment of plant growth in Mars soil analogs supplemented with hydrogels. Soil analogs consisted of sand and clay-rich material, with low organic matter content and alkaline $\mathrm{pH}$. Soils were supplemented with $10 \%(\mathrm{w} / \mathrm{w})$ potting medium and were sampled in Utah desert, in the vicinity of the Mars Desert Research Station, surrounded by soils sharing similarities in mineralogical and chemical composition to Martian soils. Height and dry biomass of spearmint (Mentha spicata) were compared under various irrigation frequencies, and seed germination of radish (Raphanus sativus) were monitored. Under limited irrigation, results indicate that the soil analogs were less capable of supporting plant growth as a comparison to potting medium. The effects of hydrogel supplementation were significant under limited irrigation and led to spearmint heights increased by 3 and $6 \%$ in clay- and sand-containing soils, respectively. Similarly, hydrogel supplementation resulted in spearmint mass increased by $110 \%$ in clay-containing soils and $78 \%$ in sand-containing soils. Additionally, while radish seeds failed to germinate in soil analogs, hydrogel supplementation allows for the germination of $27 \%$ of seeds, indicating that hydrogels might help loosening dense media with low water retention. Collectively, the results suggest that supplementation with hydrogel and plant growth substrate could help plants cope with limited irrigation and poor alkaline Mars soil analogs, and are discussed in the context of strategies for ISRUbased off-world colonization.

Keywords: in situ resource utilization (ISRU), Mars, life support systems, astrobiology, colonization, plant, hydrogel 


\section{INTRODUCTION}

Sustained human settlement on Mars will raise considerable number of challenges, among which the use of plant-based bioregenerative advanced life support systems (ALS), with the potential to provide sustainable food production, air and water recycling, and to allow the minimization of resupply missions (Ming 1989; Richards et al., 2006). Critically, such systems may likely depend on in situ resource utilization (ISRU), i.e., the use of existing materials at the settlement site, including notably water and a substrate for food production (Wheeler 2010). Together, ISRU and addition of ALS systems to exploration missions might save cargo volumes in spacecrafts, minimize safety issues, extend the length of planetary explorations and support mission success (Richards et al., 2006).

Beside the necessity of highly sealed spaces, different models for future ground-based life support systems have been studied for off-world food production, among which soilless (i.e., hydroponics or aeroponics) and soil-based systems. In comparison to soilless models, soil-based systems offer the distinct advantages to limit fertilizer and the reliance on Earth-supplied resources and to improve waste recycling (Nelson et al., 2008).

Due to the necessity of developing ISRU systems with limited supplementation, the question of whether plants can grow on Martian soils is of chief importance (Wamelink et al., 2014; FoxPowell et al., 2016). In view of fleets of orbital and landed spacecraft, our understanding of Martian soils has improved considerably over the last few decades (Billi et al., 2019). Although Martian soils contain a variety of necessary microand macronutrients in accessible forms for plants (Ehrenfreund et al., 2011; Cannon et al., 2019), substantial soils properties argue against efficient plant growth, such as high concentrations of calcium perchlorate (Hecht et al., 2009), soils with low water retention capacity (Hecht et al., 2009; Wamelink et al., 2014; Fox-Powell et al., 2016), or soils with moderately to high alkaline content (Fairén 2008; Hecht et al., 2009), a barrier for many plant species (Wamelink et al., 2005). Although large stores of underground water ice at various depth has been evidenced (Wilson et al., 2018; Piqueux et al., 2019), its availability for in situ use is still uncertain (Bullock et al., 2004; Möhlmann 2004), water stress being one of the major factors limiting crop growth and plant biomass production (Shormin 2009). The study of Terrestrial analogs of Martian regolith on plant growth in the context of limited water resources are thus critically needed.

Solutions has been reported to improve water use efficiency by plants: based on the ability of organic matter to store water available for plant growth (Hudson 1994), the supplementation with compost has been reported to improve water use efficiency and lettuce growth (Duri et al., 2020; Caporale et al., 2020).

Hydrogels are polymers able to absorb large quantities of water and fixing on plant roots. By improving water availability, they have been shown to reduce water stress and improve plant growth and survival (Montesano et al., 2015). However, some studies report negative effects on different soil types (Del Campo et al., 2011), and no study has been conducted so far with Mars soil analogs, as far as is known.
The Mars Desert Research Station (MDRS), is surrounded by a landscape that is an actual geologic Mars analog, with a mineralogy comparable to Mars, consisting of deposits of sands, clay minerals, iron oxides and traces of carbonates (Kotler et al., 2011; Direito et al., 2011).

This study reports on the effect of hydrogel supplementation on spearmint (Mentha spicata) growth parameters (i.e., height and dry biomass) under full and limited irrigation regimes, in two Mars soil analogs collected in the vincinity of the MDRS station. These soils consisted of sand and clay-rich material, with low organic matter content and alkaline $\mathrm{pH}$, and were supplemented with $10 \%$ (w/w) potting medium. Additionally, the effect of hydrogel supplementation on seed germination and emergence of radish (Raphanus sativus) was addressed in the two soils analogs.

This study is a proof of concept to help the development of Mars and Moon regoliths-based food production, where in situ use of space resources and minimal water input are needed.

\section{MATERIAL AND METHODS}

\section{Soils Sampling}

All experiments were conducted during the UCL to Mars 2018 campaign (Université catholique de Louvain) within the constraints of in situ operations in the MDRS station, a Mars analog facility operated by the Mars Society (Saint-Guillain 2019; Wuyckens et al., 2019). Soil samples were collected in the vincinity of the MDRS station, in Utah desert, at an average altitude of $1391 \mathrm{~m}$, and consisted in a white sand layer and a brown-reddish clay-rich material (hereafter referred as "sand" and "clay", respectively) (Table 1). These soils were previously analyzed for their composition during the EuroGeoMars 2009 campaign (Ehrenfreund et al., 2011), including elemental composition of nitrate, potassium, phosphorous, organic matter and carbonates. Soils were selected for their similarities with Mars soils, based on their 1) mineralogy (i.e., sand and phylosilicates [clay minerals]) and 2) composition (i.e., low amount of organic matter, iron oxides, and traces of carbonates) (Poulet et al., 2005; Chevrier and Mathé 2007; Boynton et al., 2009). Additionally, soils were analyzed in situ for their $\mathrm{pH}$ in water, indicating $\mathrm{pH}$ of 9.2 and 9.06 for sand and clay soils, respectively (Table 2).

\section{Water Holding and Release Properties of Hydrogels}

Hydrogels are polymers that are able to increase water retention, and enhance plant growth (Wang and Boogher 1987; Montesano et al., 2015; El-Asmar et al., 2017). The superabsorbent polymer used in the present study was the commercial hydrogel STOCKOSORB $^{\circledast} 660$ Medium (Evonik Industries; hereafter referred as "hydrogel"), a crosslinked potassium polyacrylic acid designed to remain active in the soil for 1-3 years. Soils were supplemented with $0.1 \%(\mathrm{w} / \mathrm{w})$ hydrogel (according to the manufacturer's instructions) prior to plant transplantation. Hydrogel were first analyzed for their ability to regenerate after drying, to mimic absorption by plant roots. A sample of $2 \mathrm{~g}$ of dry hydrogel was saturated with water, and weighed after 
TABLE 1 | Characteristics of soils used in this study. * Soils sampled at the Mars Desert Research Station location, adapted from (Ehrenfreund et al., 2011).

\begin{tabular}{|c|c|c|c|c|c|c|}
\hline Soil nature & Location & Organic matter (\%) & $\mathrm{N}$-element (ppm) & $P(p p m)$ & K (ppm) & Carbonates (\%) \\
\hline Sand * & $\mathrm{N} 38.40737^{\circ} \mathrm{W} 110.79261^{\circ}$ & 1 & $>75$ & 12 & 175 & $<1$ \\
\hline Clay * & N38.42638 W110.78342 & 2 & $>75$ & 100 & 200 & 2 \\
\hline Potting medium & - & 48 & $<10$ & 22 & 150 & - \\
\hline
\end{tabular}

TABLE 2 | Determined pH of soils and mixed soils used in this study.

\begin{tabular}{lc}
\hline Soil & pH \\
\hline Sand & 9.2 \\
Clay & 9.06 \\
Potting medium & 7.05 \\
Mix sand & 8.5 \\
Mix clay & 8.4
\end{tabular}

$10 \mathrm{~min}$ at room temperature. This sample was dried on absorbing paper at room temperature for $24 \mathrm{~h}$, and subjected to three additional hydration/dehydration cycles. Water holding capacity was measured in the soils with or without $0.1 \%(\mathrm{w} / \mathrm{w})$ hydrogel supplementation. Water holding capacity of the soil was defined as the gain in weight at saturation point divided by the dry weight of the soil, expressed in percent (Montesano et al., 2015).

\section{Experimental Design for Plant Growth}

All experiments were conducted in the greenhouse facility of MDRS station during the UCL to Mars 2018 campaign, from March 12, 2018 (Day 1) to March 25, 2018 (Day 13), with an average temperature of $24^{\circ} \mathrm{C}$ (ranging from $16.2^{\circ} \mathrm{C}$ to $30.5^{\circ} \mathrm{C}$ ) and an average air humidity of $43 \%$ during the experimental period. During this period, mean length of visible light was $14 \mathrm{~h}$ (solar irradiance $\approx 5.5 \mathrm{~kW} / \mathrm{m}^{2} /$ day (Sengupta et al., 2018).

\section{Effect of Hydrogels on Plant Growth}

For a short-term assessment of plant growth, spearmint (Mentha spicata) plants were selected for their rapid growth and their robustness under nutrient-poor conditions. Experiments aimed at addressing the effect of hydrogel amendment in Mars soil analogs, in normal or reduced irrigation conditions. To that end, plants were manually overhead irrigated with $70 \mathrm{ml}$ of water (without addition of nutrient solution), daily for normal irrigation conditions, and each 4 days for reduced irrigation conditions, below requirements for Mentha species (Clark R.J. 1980; McConkey et al., 2000; Shormin 2009). Experiments were divided into three groups of soils: potting medium ("pot. medium"), sand supplemented with $10 \%(\mathrm{w} / \mathrm{w})$ potting medium ("mix sand"), and clay supplemented with $10 \%$ (w/w) potting medium ("mix clay"). Each soil group was tested under normal or reduced irrigation regimes, performed in three independent experimental units. For each condition, plants of Mentha spicata were grown with or without $0.1 \%(\mathrm{w} / \mathrm{w})$ hydrogel supplementation. This experimental set-up resulted in three soils $\mathrm{x}$ two irrigation conditions $\mathrm{x}$ two supplementation conditions (with or without hydrogel supplementation) $\mathrm{x}$ three replicates.

Plants of Mentha spicata were transplanted at Day 1 in single pots of $9 \mathrm{~cm}$ length and $10 \mathrm{~cm}$ depth with drainage outlet. Shoot heights were recorded 13 days after transplantation (Day 13). Initial plants were $23 \pm 3 \mathrm{~cm}$ height. To normalize these variations and allow statistical comparisons, the growth of each plant was represented as a percentage of growth in comparison to its initial height (Day 1) (see Figure 2A).

Dry shoots masses were recorded for all plants 13 days after transplantation. Plants were dried in a forced air oven at $60^{\circ} \mathrm{C}$ until reaching a constant mass (Valmorbida and Boaro 2007).

\section{Effect of Hydrogels on Seed Germination and Emergence}

To monitor the first growth stages, seeds of radish (Raphanus sativus 'Scarlet Globe') were selected for their fast germination. Experiments were designed to address the effect of hydrogelsupplemented Mars soil analogs on seed germination. To that end, the following treatments were compared: potting medium ("pot. medium"), sand supplemented with $10 \%$ (w/w) potting medium ("mix sand"), clay supplemented with $10 \%(\mathrm{w} / \mathrm{w})$ potting medium ("mix clay"), sand and clay. This experimental set-up resulted in five soil conditions $\mathrm{x}$ two supplementation conditions (with or without hydrogel supplementation) $\mathrm{x}$ three replicates. For each condition, five seeds were positioned per pot at the same burial depth. The percentage of seed germination and emergence (resulting from both germination and emergence above the surface) were recorded at Day 13.

\section{Statistical Analysis}

Statistical analyses were performed with GraphPad Prism version 8.3.1, GraphPad InStat v3.10 (GraphPad Software) and SPSS v25.0 (IBM Statistics). For comparison between hydrogel and control conditions, statistical differences were determined using unpaired Student's t-tests, with a threshold of statistical significance set to 0.05 . $p$ values strictly inferior to $0.05,0.01$ and 0.001 were used to show statistically significant differences and are represented with ${ }^{\star}{ }^{\star *}$ or ${ }^{\star *}$ respectively. For multiple comparison between soils, statistical differences were determined using one-way ANOVA with Tukey's post hoc tests, with a threshold of statistical significance set to 0.05 . Different letters indicate statistically significant differences.

\section{RESULTS}

\section{Water Holding and Release Properties of Hydrogels}

Hydrogels are polymers that can absorb large quantity of water during expansion (Figure 1A). When submitted to consecutives cycles of hydration and dehydration in order to mimic absorption by plant roots and watering, respectively, data 
A
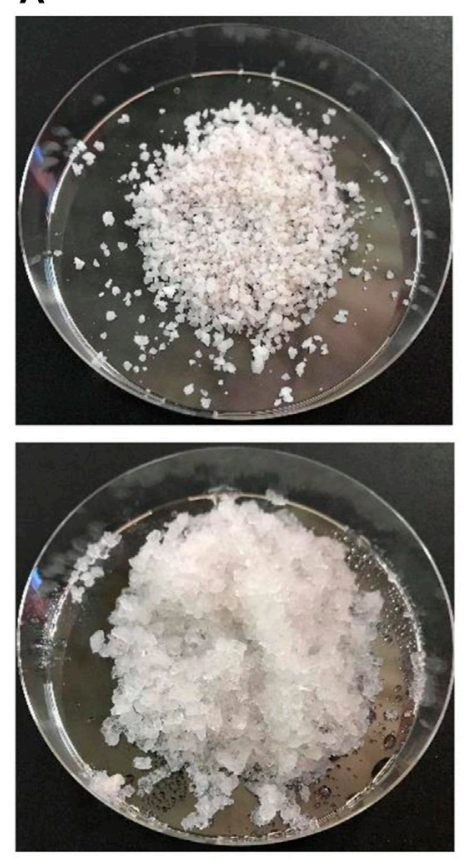

B

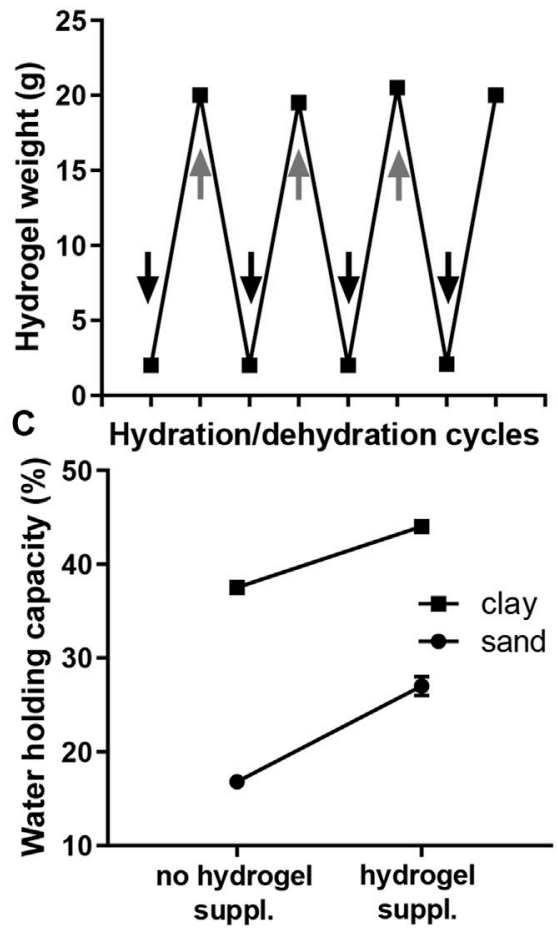

D

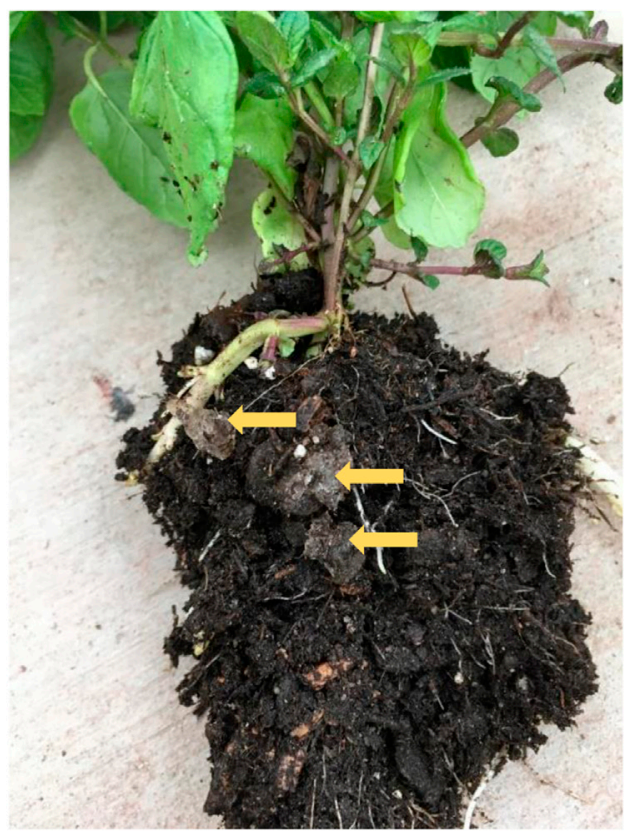

FIGURE 1 | Water holding and release properties of hydrogels (A) Sample of $1 \mathrm{~g}$ of dry hydrogel (left), and saturated with water and incubated 10 min (right) (B) Hydrogel weight during hydration/dehydration cycles. A sample of $2 \mathrm{~g}$ of dry hydrogel was saturated with water (hydration; black arrows), incubated 10 min at room temperature prior to weighing, and dried on absorbing paper at room temperature for $24 \mathrm{~h}$ (dehydration; gray arrows) (C)) Water holding capacity of sand and clay soils with (hydrogel suppl.) or without (no hydrogel suppl.) $0.1 \%$ (w/w) hydrogel supplementation (D) Hydrogels (arrows) fixed on spearmint (Mentha spicata) roots.

indicated that they absorb on average 10 times their weight in water after $10 \mathrm{~min}$, and that they efficiently regenerate for sustained periods of time (Figure 1B). The water holding capacity of sand increased from 16.8 to $27 \%$ with hydrogel supplementation (Figure 1C). The water holding capacity of clay was higher than in sand (37.5\%), and hydrogel supplementation led to additional increase to $44 \%$. Additionally, roots of Mentha spicata transplanted in potting medium amended with $0.1 \%(\mathrm{w} / \mathrm{w})$ hydrogel were able to fix on hydrogels (Figure 1D).

\section{Effect of Hydrogels on Plant Growth}

When grown in potting media, spearmint plants grew to $3 \%$ on average in 13 days, and the supplementation with hydrogels allowed for an $8 \%$ growth in comparison to their initial heights (Figure 2A), confirming the increased plant growth upon hydrogel amendment (Montesano et al., 2015). When compared to the control plants grown in potting medium without hydrogel supplementation, data indicated a significant reduction of plant growth in soil containing clay (101\% their initial values; see uppercase letters in Figure 2A). By contrast, the growths recorded in clay- or sand-containing soils with hydrogel supplementation were statistically indistinguishable from those observed in potting medium (see lowercase letters in Figure 2A). The mixing of soils with potting medium decreased the initial $\mathrm{pH}$ from 9.2 to 8.5 and from 9.06 to 8.4 , respectively (Table 2 ).

When compared with potting medium without hydrogel supplementation, the limited irrigation led to reduced growth during the course of experiments, with plant heights of 97 and $101 \%$ their initial values, respectively (see uppercase letters in Figure 2A).

Conversely, the growths recorded with hydrogel supplementation were not significantly affected among the different soils, except for clay-containing soil, albeit clay was able to support growth only in the presence of hydrogel. Under reduced irrigation frequencies, hydrogel amendment allowed for significantly improved growth in potting medium, clay- and sand-containing soils, leading to growth increased by 4,3 and $6 \%$ respectively, in comparison with nonamended conditions.

Similar trends were observed when monitoring biomasses, and the effect resulting from hydrogel amendment were significative under reduced irrigation (Figure 2B). In comparison with nonamended conditions, hydrogel supplementation resulted in plant masses increased by $34 \%$ in potting medium, $110 \%$ in claycontaining soils and $78 \%$ in sand-containing soils. Consistently, the plant masses recorded with hydrogel supplementation were not significantly different among the different soils or irrigation regimes. 

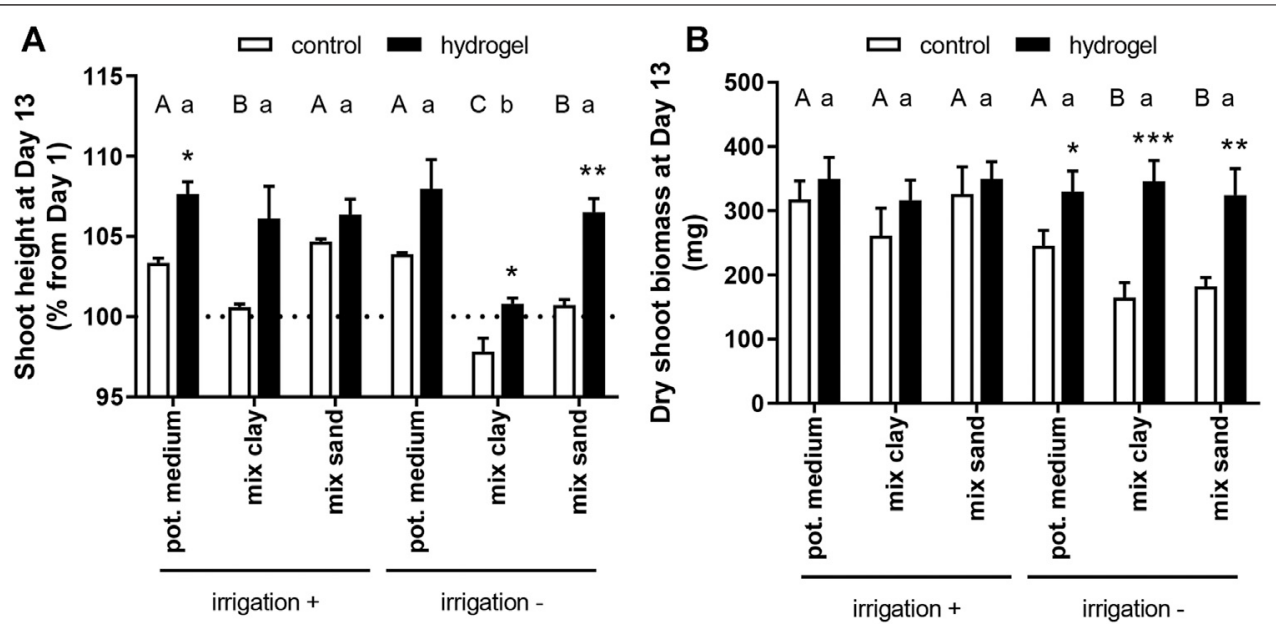

FIGURE 2 | Shoots heights (A) and dry shoots biomasses (B) of spearmint (Mentha spicata) 13 days after transplantation (Day 13), with (hydrogel) or without (control) $0.1 \%(w / w)$ hydrogel supplementation, under varying irrigation conditions. Pots were filled with soils from MDRS location (see Table 1) supplemented with $10 \%$ $(\mathrm{w} / \mathrm{w})$ potting medium or with potting medium alone (mix clay, mix sand and pot. medium, respectively). Plants were either daily watered (irrigation + ) or each 4 days (irrigation -). All data are means of three replications. Statistical analysis for comparison between control and hydrogel conditions: unpaired Student's t-test. ${ }^{\star} p<0.05,{ }^{\star \star} p<0.01,{ }^{* \star *} p<0.001$. For comparison between soils: one-way ANOVA with Tukey's post hoc test. Different uppercase (control) or lowercase (hydrogel) letters indicate values significantly different from each other.

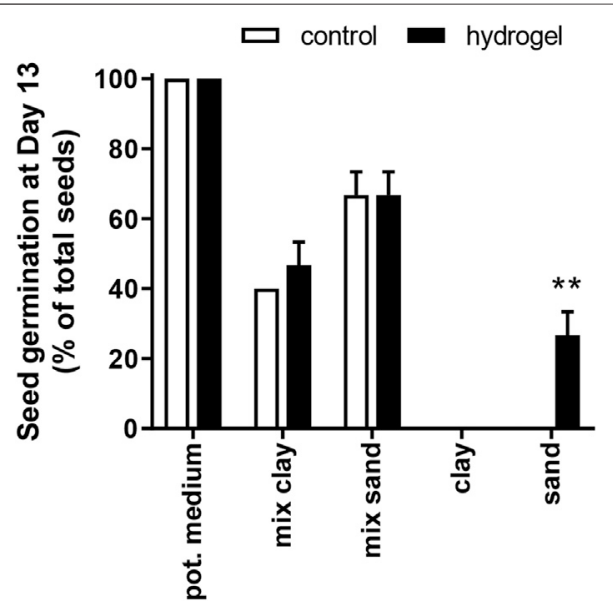

FIGURE 3 | Percentage of seed germination of radish (Raphanus sativus) after 13 days. For each condition, five seeds were positioned per pot, filled with potting medium, or soils from MDRS location (see Table 1) supplemented with $10 \%(\mathrm{w} / \mathrm{w})$ potting medium, or soils alone, respectively, with (hydrogel) or without (control) $0.1 \%(\mathrm{w} / \mathrm{w})$ hydrogel supplementation. Data are means of three replications. Statistical analysis for comparison between control and hydrogel conditions: unpaired Student's t-test. ${ }^{* *} p<0.01$

\section{Effect of Hydrogels on Seed Germination and Emergence}

All the seeds germinated in pots filled with potting medium regardless of the presence or absence of hydrogel amendment, indicating the absence of toxicity of hydrogels on seed germination in these conditions (Figure 3). A reduced germination or emergence were observed in soils containing clay, and sand to a lesser extent, allowing for the germination and emergence of 40 and $66 \%$ of seeds respectively, without significative effect of hydrogel supplementation. In control conditions, seeds of radish failed to show any germination or emergence after 13 days in pots only filled with clay or sand, which both create dense media largely unfavorable for germination. Similarly, clay did not support germination or emergence of seeds of radish under hydrogel supplementation.

Additionally, hydrogel supplementation allows however for the germination and emergence of $27 \%$ of seeds in average in sand.

\section{DISCUSSION}

This work takes place in body of studies that address the capacity of regolith simulants to support plant growth, in the context of ISRU for off-world colonization (Wamelink et al., 2014; Guinan 2018; Wamelink et al., 2019; Eichler et al., 2021). As a precursor to human visitations and future off-world agricultural systems, research regarding plant response to simulated Martian environment is of chief importance.

Our current knowledge of the Martian surface highly suggests that several mineral and chemical properties encountered will likely constitute barriers for plant growth. Firstly, Mars is covered with sand-sized particles with various cohesive strength (Bishop et al., 2002; Arvidson et al., 2004a; Arvidson et al., 2004b), as well as traces of clay minerals (Milliken et al., 2010). Low amounts of organic matter and carbon stored in carbonates have been found in specific regions or rock fractures (Boynton et al., 2009; Leshin et al., 2013; Moyano-Cambero et al., 2017). Secondly, the measurements so far indicate that soils are alkaline, with $\mathrm{pH}$ ranging from eight to nine (Fairén 2008), which may be problematic for many plant species, by decreasing nutrients 
availability for plants (Wamelink et al., 2005). Finally, the availability of water for optimal plant cultivation might constitute one of the biggest issues raised by ISRU-based food production systems on Mars.

Several studies addressed the growth of plants in Martian regolith simulants, but some display critical differences with the chemical or mineralogical composition of Martian regolith such as the presence of organic matter (Seiferlin et al., 2008), or $\mathrm{pH}$ below the alkaline $\mathrm{pH}$ recorded at the Phoenix lander site (Fairén 2008; Hecht et al., 2009; Kounaves et al., 2010; McElhoney et al., 2014).

The proposed study tends to integrate the aforementioned parameters, and to assess the effect of hydrogel on plant growth in Mars soil analogs, consisting in sand and clay-rich material with low amount organic matter and alkaline $\mathrm{pH}$.

Results indicate that hydrogels improved the water retention capacity of sand, and to a lesser extent, clay soil, the latter having a high intrinsic retention capacity (Montesano et al., 2015). This further confirms the interesting water holding and release properties of hydrogel in the tested conditions.

Although experiments were limited to the first growth stages of spearmint (Mentha spicata), hydrogel supplementation improved plant growth under full irrigation regime, albeit limited growth in the control conditions. The latter can be due either to the stress resulting from transplantation, the relatively low air humidity or the alkaline $\mathrm{pH}$ in the mixed soils. This mixing of soils with potting medium partially mitigate their alkalinity, leading to $\mathrm{pH}$ values in the range of $\mathrm{pH}$ of Martian soils (Fairén 2008).

Mint is a crop with a high water requirement during its active growth period (Shormin 2009). Due to the limited availability of liquid water for ISRU on Mars, the effects of hydrogel supplementation were then investigated under low irrigation conditions. The soil analogs, together with the limited irrigation frequency, were less capable of supporting plant growth as a comparison to potting medium. This indeed resulted in culture conditions well beyond Mentha species requirements i.e., slightly acidic $\mathrm{pH}$ media (Valmorbida and Boaro 2007; Shormin 2009; Mohammadi and Asadi-Gharneh 2018) and frequent irrigation (Clark R.J. 1980; McConkey et al., 2000; Shormin 2009). Under water stress, N-uptake as well as vegetative growth and biomass production of plants significantly decrease, leading to more pronounced effect of hydrogel supplementation under water deficit, both on plant heights and biomass. These observations are consistent with reports showing that water stress significantly decreases plant height (Shormin 2009) as well as findings on Argania spinosa in arid region (C Defaa 2015), and on cucumber and basil plants in sandy soils (Montesano et al., 2015). Moreover, a wilting of main branches of plants was observed in clay-containing soils, which appeared to be cohesive and unfavorable for plant growth, confirming that the deleterious effect of claycontaining soil was more pronounced under low irrigation frequencies. Despite the ability of organic matter to store water, the supplementation with potting media appeared insufficient to cope with water deficit and to support efficient plant growth in the two soil analogs.
Collectively, this suggests that supplementation with hydrogel and traditional plant growth substrate allows for enhanced plant growth in poor alkaline Mars soil analogs under water deficit.

Additionally, the soil analogs were unable to support seed germination and emergence of radish (Raphanus sativus), whereas hydrogel supplementation allowed for seed germination in sand, suggesting that hydrogels could help loosening dense soils. While preliminary, these results rise the hypothesis that hydrogels could facilitate seed germination in soils as the cohesive sand-like soils encountered in Mars (Arvidson et al., 2004a).

This study will require more replications to strengthen the findings highlighted in the present work, and to confirm that the beneficial effects of hydrogels are observed for the different stages of plant growth. The percentage of seed germination recorded in this study results from both germination and emergence above the surface, and additional experiments will be needed to delineate whether the effects of hydrogel are related to germination itself or to emergence of sprouts. Moreover, because benefits of hydrogel supplementation are generally related to the concentration applied to the soil, one can assume that higher concentrations could improve the plant growth further. Given the absolute necessity of sealed life support systems for future agricultural systems on Mars, further experiments will have to be reproduced in a full climate control environment to reach culture conditions relevant to future greenhouses on Mars (e.g., optimal temperature and air humidity), and to ensure the reproducibility of the findings highlighted in the present work.

More globally, this work further confirms the need of soil supplementation outlined by several studies to support the growth of plants. The use of fertilizer has been proposed as a source of nutrient to increase the crop yield (Li et al., 2016; Yamamoto et al., 2016). This notably comprises supplementation with nitrogen (through direct $\mathrm{NH}_{4} / \mathrm{NO}_{3}$ supplementation or nitrogen fixing bacteria), an essential nutrient for plant growth, which is absent in JSC-Mars-1A simulant (Wamelink et al., 2019), although nitrate in sedimentary and aeolian deposits has been detected in specific regions by Curiosity Mars Science Laboratory within Gale crater (Stern et al., 2015). Other reports highlight the importance of soil acidification to improve the plant viability, and the necessity of detoxifying substrates from perchlorates (Eichler et al., 2021), through e.g., perchlorate-reducing bacteria (Coates John et al., 1999).

This work is a short-term assessment conducted within the constraints of in situ operations and will require further studies on other plants, Mars soil analogs and hydrogels. Together, these results should be considered as a proof of concept that indicate the potential interest of hydrogels to limit water input in ISRUbased food production systems.

\section{DATA AVAILABILITY STATEMENT}

The raw data supporting the conclusions of this article will be made available by the authors, without undue reservation. 


\section{AUTHOR CONTRIBUTIONS}

FP conceived and designed the experiments, collected the data, performed the analysis and wrote the paper.

\section{FUNDING}

FP is recipient of a postdoctoral fellow from the Université catholique de Louvain.

\section{REFERENCES}

Arvidson, R. E., Anderson, R. C., Bartlett, P., Bell, J. F., 3rd, Blaney, D., Christensen, P. R., et al. (2004a). Localization and Physical Properties Experiments Conducted by Spirit at Gusev Crater. Science 305, 821-824. doi:10.1126/ science.1099922

Arvidson, R. E., Anderson, R. C., Bartlett, P., Bell, J. F., 3rd, Christensen, P. R., Chu, P., et al. (2004b). Localization and Physical Property Experiments Conducted by Opportunity at Meridiani Planum. Science 306, 1730-1733. doi:10.1126/ science. 1104211

Billi, D., Verseux, C., Fagliarone, C., Napoli, A., Baqué, M., and de Vera, J.-P. (2019). A Desert Cyanobacterium under Simulated Mars-like Conditions in Low Earth Orbit: Implications for the Habitability of Mars. Astrobiology 19, 158-169. doi:10.1089/ast.2017.1807

Bishop, J. L., Murchie, S. L., Pieters, Carlé. M., Pieters, C. M., and Zent, A. P. (2002). A Model for Formation of Dust, Soil, and Rock Coatings on Mars: Physical and Chemical Processes on the Martian Surface. J.-Geophys.-Res. 107, 7-17. doi:10.1029/2001je001581

Boynton, W. V., Ming, D. W., Kounaves, S. P., Young, S. M. M., Arvidson, R. E., Hecht, M. H., et al. (2009). Evidence for Calcium Carbonate at the Mars Phoenix Landing Site. Science 325, 61-64. doi:10.1126/science.1172768

Bullock, M. A., Moore, J. M., and Mellon, M. T. (2004). Laboratory Simulations of Mars Aqueous Geochemistry. Icarus 170, 404-423. doi:10.1016/ j.icarus.2004.03.016

Cannon, K. M., Britt, D. T., Smith, T. M., Fritsche, R. F., and Batcheldor, D. (2019). Mars Global Simulant MGS-1: A Rocknest-Based Open Standard for Basaltic Martian Regolith Simulants. Icarus 317, 470-478. doi:10.1016/j.icarus.2018.08.019

Caporale, A. G., Vingiani, S., Palladino, M., El-Nakhel, C., Duri, L. G., Pannico, A., et al. (2020). Geo-mineralogical Characterisation of Mars Simulant MMS-1 and Appraisal of Substrate Physico-Chemical Properties and Crop Performance Obtained with Variable green Compost Amendment Rates. Sci. Total Environ. 720. 137543.doi:10.1016/j.scitotenv.2020.137543

Chevrier, V., and Mathé, P. E. (2007). Mineralogy and Evolution of the Surface of Mars: A Review. Planet. Space Sci. 55, 289-314. doi:10.1016/j.pss.2006.05.039

Clark, R., and Menary, R. (1980). The Effect of Irrigation and Nitrogen on the Yield and Composition of Peppermint Oil (Mentha Piperita L.). Aust. J. Agric. Res. 31, 489-498. doi:10.1071/ar9800489

Coates, J. D., Michaelidou, U., Bruce, R. A., O'Connor, S. M., Crespi, J. N., and Achenbach, L. A. (1999). Ubiquity and Diversity of Dissimilatory (Per)chlorateReducing Bacteria. Appl. Environ. Microbiol. 65, 5234-5241. doi:10.1128/ aem.65.12.5234-5241.1999

Defaa, C., Achour, A., El Mousadik, A., and Maanda, F. (2015). Effets de l'hydrogel sur la survie et la croissance des plantules d'arganier sur une parcelle de régénération en climat aride. J. App. Biosci. 92, 8586-8594. doi:10.4314/ jab.v92i1.3

Del Campo, A. D., Hermoso, J., Flors, J., Lidon, A., Navarro-Cerrillo, R. M., Rafael, M., et al. (2011). Nursery Location and Potassium Enrichment in Aleppo pine Stock 2. Performance under Real and Hydrogel-Mediated Drought Conditions. Forestry 84, 235-245. doi:10.1093/forestry/cpr009

Direito, S. O. L., Ehrenfreund, P., Marees, A., Staats, M., Foing, B., Röling, W. F. M., et al. (2011). A Wide Variety of Putative Extremophiles and Large BetaDiversity at the Mars Desert Research Station (Utah). Int. J. Astrobiology 10, 191-207. doi:10.1017/s1473550411000012

\section{ACKNOWLEDGMENTS}

This work could not have been conducted without the involvement of the entire UCL to Mars 2018 crew: Bastien Baix, Martin Roumain, Michael Saint-Guillain, Ariane Sablon, Sophie Wuyckens, Mario Sundic and Maximilien Richald, who all contributed to a relevant and inspiring campaign. I also gratefully acknowledge the Mars Society, especially Robert Zubrin, Shannon Rupert and the Mission Support team, for creating the conditions that make rotations at the MDRS relevant to Mars analog sojourns.

Duri, Luigi. G., El-Nakhel, Christophe., Caporale, Antonio. G., Ciriello, Michele., Graziani, Giulia., Pannico, Antonio., et al. (2020). Mars Regolith Simulant Ameliorated by Compost as In Situ Cultivation Substrate Improves Lettuce Growth and Nutritional Aspects. Plants, 9, 628

Ehrenfreund, P., Röling, W. F. M., Thiel, C. S., Quinn, R., Sephton, M. A., Stoker, C., et al. (2011). Astrobiology and Habitability Studies in Preparation for Future Mars Missions: Trends from Investigating Minerals, Organics and Biota. Int. J. Astrobiology 10, 239-253. doi:10.1017/s1473550411000140

Eichler, A., Hadland, N., Pickett, D., Masaitis, D., Handy, D., Perez, A., et al. (2021). Challenging the Agricultural Viability of Martian Regolith Simulants. Icarus 354. 114022.doi:10.1016/j.icarus.2020.114022

El-Asmar, J., Jaafar, H., Bashour, I., Farran, M. T., and Saoud, I. P. (2017). Hydrogel Banding Improves Plant Growth, Survival, and Water Use Efficiency in Two Calcareous Soils. Clean. Soil Air Water 45, 1700251. doi:10.1002/ clen.201700251

Fairén, A. G. (2008). Finding of Unusual Soil on Mars Could Stem from Tools Used. Nature 456, 870. doi:10.1038/456870c

Fox-Powell, M. G., Hallsworth, J. E., Cousins, C. R., and Cockell, C. S. (2016). Ionic Strength Is a Barrier to the Habitability of Mars. Astrobiology 16, 427-442. doi:10.1089/ast.2015.1432

Guinan, Edward. Francis. (2018). 'Mars Gardens in the University - Red Thumbs: Growing Vegetables in Martian Regolith Simulant. AAS Meet. \# 231, 401-406.

Hecht, M. H., Kounaves, S. P., Quinn, R. C., West, S. J., Young, S. M. M., Ming, D. W., et al. (2009). Detection of Perchlorate and the Soluble Chemistry of Martian Soil at the Phoenix lander Site. Science 325, 64-67. doi:10.1126/science.1172466

Hudson, Berman. D. (1994). 'Soil Organic Matter and Available Water Capacity. J. Soil Water Conservation 49, 189

Kotler, J. M., Quinn, R. C., Foing, B. H., Martins, Z., and Ehrenfreund, P. (2011). Analysis of mineral Matrices of Planetary Soil Analogues from the Utah Desert. Int. J. Astrobiology 10, 221-229. doi:10.1017/s1473550411000103

Kounaves, S. P., Hecht, M. H., Kapit, J., Gospodinova, K., DeFlores, L., Quinn, R. C., et al. (2010). 'Wet Chemistry Experiments on the 2007 Phoenix Mars Scout Lander mission: Data Analysis and Results. J. Geophys. Res. Planets 115. doi:10.1029/2009je003424

Leshin, L. A., Mahaffy, P. R., Webster, C. R., Cabane, M., Coll, P., Conrad, P. G., et al. (2013). Volatile, Isotope, and Organic Analysis of Martian Fines with the Mars Curiosity Rover. Science 341. 1238937.doi:10.1126/science.1238937

Li, B., Dong, C., Chu, Z., Zhang, W., Wang, M., Liu, H., et al. (2016). Synthesis, Characterization and Application of Ion Exchange Resin as a Slow-Release Fertilizer for Wheat Cultivation in Space. Acta Astronautica 127, 579-586. doi:10.1016/j.actaastro.2016.06.048

McConkey, M. E., Gershenzon, J., and Croteau, R. B. (2000). Developmental Regulation of Monoterpene Biosynthesis in the Glandular Trichomes of Peppermint. Plant Physiol. 122, 215-224. doi:10.1104/pp.122.1.215

McElhoney, Kyle., O’Neil, Glen., and Kounaves, Samuel. (2014). "Extraterrestrial Analysis," in Environmental Analysis by Electrochemical Sensors and Biosensors (Springer), 131-151. doi:10.1007/978-1-4939-0676-5_6

Milliken, R. E., Grotzinger, J. P., and Thomson, B. J. (2010). Paleoclimate of Mars as Captured by the Stratigraphic Record in Gale Crater. Geophys. Res. Lett. 37. doi:10.1029/2009gl041870

Ming, D. W., and Henninger, D. L. (1989). Lunar Base Agriculture: Soils for Plant Growth. Madison, WI: American Society of Agronomy, Crop Science Society of America, and Soil Science Society of America 
Mohammadi, M., and Asadi-Gharneh, H. A. (2018). How the Morphological Properties of Mentha longifolia.(L.) Huds. May Be Affected by Geographical Differences. J. Photochem. Photobiol. B: Biol. 178, 237-242. doi:10.1016/ j.jphotobiol.2017.10.032

Möhlmann, D. T. F. (2004). Water in the Upper Martian Surface at Mid- and LowLatitudes: Presence, State, and Consequences. Icarus 168, 318-323. doi:10.1016/ j.icarus.2003.11.008

Montesano, F. F., Parente, A., Santamaria, P., Sannino, A., and Serio, F. (2015). Biodegradable Superabsorbent Hydrogel IncreasesWater Retention Properties of Growing Media and Plant Growth. Agric. Agric. Sci. Proced. 4, 451-458. doi:10.1016/j.aaspro.2015.03.052

Moyano-Cambero, C. E., Trigo-Rodríguez, J. M., BenitoTrigo-Rodríguez, M. I., Alonso-Azcárate, J., Lee, M. R., Mestres, N., et al. (2017). Petrographic and Geochemical Evidence for Multiphase Formation of Carbonates in the Martian Orthopyroxenite Allan Hills 84001. Meteorit Planet. Sci. 52, 1030-1047. doi:10.1111/maps.12851

Nelson, M., Dempster, W. F., and Allen, J. P. (2008). Integration of Lessons from Recent Research for "Earth to Mars" Life Support Systems. Adv. Space Res. 41, 675-683. doi:10.1016/j.asr.2007.02.075

Piqueux, S., Buz, J., Edwards, C. S., Bandfield, J. L., Kleinböhl, A., Kass, D. M., et al. (2019). Widespread Shallow Water Ice on Mars at High Latitudesand Midlatitudes'Widespread Shallow Water Ice on Mars at High Latitudesand Midlatitudes. Geophys. Res. Lett. 46, 14290-14298. doi:10.1029/2019g1083947

Poulet, F., Bibring, J. P., Bibring, J.-P., Mustard, J. F., Gendrin, A., Mangold, N., et al.Team The Omega (2005). Phyllosilicates on Mars and Implications for Early Martian Climate. Nature 438, 623-627. doi:10.1038/nature04274

Richards, J. T., CoreyPaul, K., Paul, A.-L., Ferl, R. J., Wheeler, R. M., and Schuerger, A. C. (2006). Exposure ofArabidopsis Thalianato Hypobaric Environments: Implications for Low-Pressure Bioregenerative Life Support Systems for Human Exploration Missions and Terraforming on Mars. Astrobiology 6, 851-866. doi:10.1089/ast.2006.6.851

Saint-Guillain, M. (2021). "Robust Operations Management on Mars," in Proceedings of the International Conference on Automated Planning and Scheduling, Berkeley, California USA, July 11, 2019, vol. 29, 368-376.

Seiferlin, K., Ehrenfreund, P., Garry, J., Gunderson, K., Hütter, E., Kargl, G., et al. (2008). Simulating Martian Regolith in the Laboratory. Planet. Space Sci. 56, 2009-2025. doi:10.1016/j.pss.2008.09.017

Sengupta, M., Xie, Y., Lopez, A., Habte, A., Maclaurin, G., and Shelby, J. (2018). The National Solar Radiation Data Base (NSRDB). Renew. Sust. Energ. Rev. 89, 51-60. doi:10.1016/j.rser.2018.03.003

Shormin, T., Khan, M., and Alamgir, M. (2009). Response of Different Levels of Nitrogen Fertilizer and Water Stress on the Growth and Yield of Japanese Mint (Mentha Arvensis). Bangladesh J. Scientific Ind. Res. 44 (1), 137-145.

Stern, J. C., Sutter, B., Freissinet, C., Navarro-González, R., McKay, C. P., Jr., Archer, P. D., et al. (2015). Evidence for Indigenous Nitrogen in Sedimentary and Aeolian Deposits from the Curiosity Rover Investigations at Gale Crater, Mars. Proc. Natl. Acad. Sci. USA 112, 4245-4250. doi:10.1073/pnas.1420932112
Valmorbida, J., and Boaro, C. S. F. (2007). Growth and Development of Mentha Piperita L. In Nutrient Solution as Affected by Rates of Potassium. Braz. Arch. Biol. Technol. 50, 379-384. doi:10.1590/s1516-89132007000300003

Wamelink, G. W. W., Goedhart, P. W., Van Dobben, Han. F., Van Dobben, H. F., and Berendse, F. (2005). Plant Species as Predictors of Soil pH: Replacing Expert Judgement with Measurements. J. Vegetation Sci. 16, 461-470. doi:10.1111/ j.1654-1103.2005.tb02386.x

Wamelink, G. W. W., Frissel, J. Y., Krijnen, W. H. J., and Verwoert, M. R. (2019). Crop Growth and Viability of Seeds on Mars and Moon Soil Simulants. Open Agric. 4, 509-516. doi:10.1515/opag-2019-0051

Wamelink, G. W. W., Frissel, J. Y., Krijnen, W. H. J., Verwoert, M. R., and Goedhart, P. W. (2014). Can Plants Grow on Mars and the Moon: A Growth Experiment on Mars and Moon Soil Simulants. PLoS One 9. e103138.doi:10.1371/journal.pone.0103138

Wang, Y.-T., and Boogher, C. A. (1987). Effect of a Medium-Incorporated Hydrogel on Plant Growth and Water Use of Two Foliage Species. J. Environ. Hortic. 5, 127-130. doi:10.24266/0738-2898-5.3.127

Wheeler, R. (2010). Plants for Human Life Support in Space: from Myers to Mars. Gravit. Space Res. 23, 25-36.

Wilson, J. T., Eke, V. R., Massey, R. J., Elphic, Richard. C., Feldman, William. C., Elphic, R. C., et al. (2018). Equatorial Locations of Water on Mars: Improved Resolution Maps Based on Mars Odyssey Neutron Spectrometer Data. Icarus 299, 148-160. doi:10.1016/j.icarus.2017.07.028

Wuyckens, S., Giammanco, A., Cortina Gil, E., and Demin, P. (2019). A Portable Muon Telescope Based on Small and Gas-Tight Resistive Plate chambers. Phil. Trans. R. Soc. A. 377. 20180139.doi:10.1098/rsta.2018.0139

Yamamoto, C. F., Pereira, E. I., Mattoso, L. H. C., Matsunaka, T., and Ribeiro, C. (2016). Slow Release Fertilizers Based on Urea/urea-Formaldehyde Polymer Nanocomposites. Chem. Eng. J. 287, 390-397. doi:10.1016/ j.cej.2015.11.023

Conflict of Interest: The author declares that the research was conducted in the absence of any commercial or financial relationships that could be construed as a potential conflict of interest.

Publisher's Note: All claims expressed in this article are solely those of the authors and do not necessarily represent those of their affiliated organizations, or those of the publisher, the editors and the reviewers. Any product that may be evaluated in this article, or claim that may be made by its manufacturer, is not guaranteed or endorsed by the publisher.

Copyright $(\odot 2021$ Peyrusson. This is an open-access article distributed under the terms of the Creative Commons Attribution License (CC BY). The use, distribution or reproduction in other forums is permitted, provided the original author(s) and the copyright owner(s) are credited and that the original publication in this journal is cited, in accordance with accepted academic practice. No use, distribution or reproduction is permitted which does not comply with these terms. 